\title{
Pasting and gel texture properties of starch-molasses combinations
}

\author{
Gülden GÖKŞEN ${ }^{1 \star}$, Hacı Ibrahim EKIZ ${ }^{1}$
}

\begin{abstract}
Molasses replacement by sugar are used in new product formulations for enrichment quality of products in the food industry. The influence of addition of wheat and corn starches on grape and carob molasses at different concentrations in distilled water (from 0 to $30 \% \mathrm{w} / \mathrm{w}$ ) and holding temperatures $\left(90\right.$ to $98^{\circ} \mathrm{C}$ ), pasting and gel texture properties were determined. Pasting parameters for carob molasses-starch combinations were higher than grape molasses-starch, due to presence of different sugar content in carob molasses. Textural properties of carob molasses-wheat starch interactions were affected more highly than grape molasses-wheat starch interactions. The starch varieties affected strongly the textural parameters (hardness, adhesiveness, cohesiveness, springiness) of gels. All sample gels lost viscous and soft sludge properties at increasing holding temperature especially $98{ }^{\circ} \mathrm{C}$. These results showed that molasses and starch varities and different holding temperature could facilitate development of optimum final products with desired improved pasting and textural properties.
\end{abstract}

Keywords: corn starch; wheat starch; grape molasses; carob molasses; pasting properties; textural profile.

Practical Application: Different molasses-starch combinations: pasting parameters and textural properties.

\section{Introduction}

Molasses (pekmez) is a traditional and healthy product in Turkey. It is concentrated up to $70-80 \%$ soluble dry matter content from sugar rich fruits such as grape, carob, prune, mulberry, and sugar beet (Sert et al., 2009).

Molasses provides nutritional value and carbohydrate source for consumer. Molasses has a high natural sugar content, so it is used as an alternative to jam, sugar or honey (Sengül et al., 2007). In addition, molasses can be used as a natural sweetener, colourant and flavouring agent in ice-cream toppings, compotes, pastries, biscuits, desserts. The carbohydrates of grape molasses are only glucose and fructose in almost equal quantities, whereas the carbohydrates in carob molasses has a high content of sucrose (at more than 30\%), glucose and fructose (Akkaya et al., 2012). In recent years carob is used for new food formulations because it looks like cocoa in apperance and is often used as a cocoa substitute and chocolate (Sengül et al., 2007). Mineral and sugar compositions of carob molasses play a vital role in human nutrition. It provides benefits of enriched mineral content for healthier growth and prevention and healing of diseases (Ozcan et al., 2007).

Starch is the major source of carbohydrate in the human diet and a valuable ingredient for food products. Starch is used extensively in the food products as a thickener, gelling, bulking and water retention agent. Starch undergoes various physicochemical changes during the heating and cooling process, forming viscoelastic gels and changing texture becomes starch paste (Sun et al., 2014). The gelatinization, pasting, textural, swelling and digestibility properties of starch show differences according to variety and the processing conditions (BeMiller, 2011).

Sugars have significant effects on starch retrogradation. Sugars of low molecular weight are commonly used as functional ingredients to improve food product quality (Baek et al., 2004). Recrystallization of starch has a considerable commercial interest, because starch retrogradation is the major factor contributing to the textural properties of starch-based food products.

Several researchers have studied the effects of sugars and syrups on the gelatinization, pasting textural properties and starch retrogradation (Gunaratne et al., 2007; Teng et al., 2013; Sun et al., 2014; Wang et al., 2016). Most sugars reduce the amount of amylose leaching, demonstrate anti-plasticizing effects and contribute to the textural properties of starch-based food products but delay the gelatinization by increasing the gelatinization temperature during a longer storage period (Sun et al., 2014; Wang et al., 2016). The presence of sugars used as functional ingredients to improve food product quality in commercial (Wang et al., 2016). According to a report by Chang et al. (2004), disaccharide (sucrose) had a greater effect in retarding gelatinization than monosaccharide (glucose). When various sugars were added to starch and heated with the Rapid Visco-Analyser (RVA) the monosaccharide produced less decrease in paste consistency than the higher molecular weight sugars (sucrose or polydextrose) which exerted more pronounced effects (Kim \& Walker, 1992). In addition, the monosaccharides inhibited sweet potato starch retrogradation, while sucrose enhanced retrogradation (Cho \& Yoo, 2010). 
As shown in the previous studies have focused on single sugar systems, although mixtures of monosaccharides or disaccharides are used for various food formulations (Iwe \& Agiriga, 2014; Akkaya et al., 2012; BeMiller, 2011). Especially when molasses is used as a natural sugar blends in the food formulations such as ready-to-eat breakfast cereals, spreadable product and snacks, they provide health and nutritional benefit. Therefore understanding the component interactions in the starch-molasses composite system is also important for improving the pasting and textural properties of wheat and corn starch in grape and carob molasses and new product development of starch-based products.

The aim of this study, different RVA holding temperatures (90 to $98^{\circ} \mathrm{C}$ ), concentrations of molasses (0 to $30 \% \mathrm{w} / \mathrm{w}$ ) and botanical origin of starch (corn and wheat) and molasses (grape and carob) have been studied to determine their interactions and quality of end product. The addition of molasses to starch in suitable proportion and temperature can be a feasible alternative to the formulation of starch based traditional foods or new products.

\section{Materials and methods}

Corn starch, wheat starch, grape and carob molasses were purchased locally in Turkey. Sugar levels were measured according to the high-performance liquid chromatography (HPLC) method of Alasalvar et al. (2005). Sugars were extracted from grape and carob molasses $(2.5 \mathrm{~g})$ with $80 \mathrm{~mL}$ of acetonitrile/water $(1: 1 \mathrm{v} / \mathrm{v})$. Column temperature was at ambient temperature and the mobile phase was a mixture of acetonitrile and HPLC-grade water at a ratio of $85: 15(\mathrm{v} / \mathrm{v})$ at a flow rate of $0.5 \mathrm{~mL} / \mathrm{min}$. Identified sugars were quantified by comparison of the peak area obtained with those of standard sugars. Total soluble solids of the molasses were measured by Abbe refractometer at $20^{\circ} \mathrm{C}$ and expressed in ${ }^{\circ}$ Brix.

Experimental design was used to analyze of gel characteristics according to three processing variables: starch varieties (corn and wheat), molasses cultivars (grape and carob), molasses concentrations $(0,1,5,10,20,30 \% \mathrm{w} / \mathrm{w})$ and holding temperatures $\left(90,92,95\right.$ and $\left.98{ }^{\circ} \mathrm{C}\right)$ (Table 1). The independent variables considered were the concentration of molasses and the holding temperature. The dependent variables were pasting and textural parameters.

Table 1. Experimental design according to independent variables and varieties of starch and molasses.

\begin{tabular}{cccc}
\hline $\begin{array}{c}\text { Starch } \\
\text { Variety }\end{array}$ & $\begin{array}{c}\text { Grape/Carob } \\
\text { Molasses } \\
\text { Concentration } \\
(\%)\end{array}$ & $\begin{array}{c}\text { Water } \\
\text { Concentration } \\
(\%)\end{array}$ & $\begin{array}{c}\text { Holding } \\
\text { Temperature } \\
\left({ }^{\circ} \mathrm{C}\right)\end{array}$ \\
\hline Corn/Wheat & 0 & 100 & $90,92,95,98$ \\
& 1 & 99 & \\
& 5 & 95 & \\
& 10 & 90 & \\
& 20 & 80 & \\
& 30 & 70 & \\
\hline
\end{tabular}

\subsection{Pasting properties}

Pasting properties of starch-molasses mixtures were measured by Rapid Visco Analyser (Newport Scientific, RVA- 4, Warriewood, Australia). The corn/wheat starch (3.0 g, $14 \mathrm{~g} / 100 \mathrm{~g}$ moisture basis) were weighed directly in the RVA canister and the different concentration of grape/carob molasses in distilled water were added to obtain a sample weight of $28.0 \mathrm{~g}$. The formed slurry samples were heated to $50^{\circ} \mathrm{C}$ and stirred at $160 \mathrm{rpm}$ for $10 \mathrm{~s}$. Then, the samples were held at $50^{\circ} \mathrm{C}$ for $1 \mathrm{~min}$, and then heated up to different temperature $\left(90,92,95\right.$ or $\left.98^{\circ} \mathrm{C}\right)$ for $3.42 \mathrm{~min}$ and held at that temperature for $5 \mathrm{~min}$, and cooled down to $50^{\circ} \mathrm{C}$ for $6.18 \mathrm{~min}$. The concentration of grape/carob molasses was $0 \%, 1 \%, 5 \%, 10 \%, 20 \%$ and $30 \%(\mathrm{w} / \mathrm{w})$ in distilled water. Corn/Grape (CG), Corn/Carob (CC), Wheat/Grape (WG), Wheat/Carob (WC) were codes of the samples. Parameters recorded were pasting temperature, peak viscosity (maximum paste viscosity), trough viscosity (minimum viscosity at $95^{\circ} \mathrm{C}$ ) and final viscosity (viscosity at $50{ }^{\circ} \mathrm{C}$ ). When kept at the maximum temperature and mixed, the starch molecules are shear thinning and then the viscosity decreases to the trough viscosity.

\subsection{Textural profile analysis of gels}

Immediately after the measurements in the RVA, samples were poured into plastic rings with an inner diameter of $25 \mathrm{~mm}$ and a height of $10 \mathrm{~mm}$. The pastes were cooled at room temperature, and the gels were removed from the rings after $2 \mathrm{~h}$. The gels were analysed their texture profile. The gel cylinders were measured with a texture analyser (TA-XT2, Stable Micro Systems, Surrey, $\mathrm{UK}$ ). An aluminium probe of $35 \mathrm{~mm}$ diameter (PP35; Stable Micro Systems, Surrey, UK) was used and the crosshead speed was adjusted to $1 \mathrm{~mm} / \mathrm{s}$. The deformation level was set at $50 \%$ strain of the original sample height. Compression was repeated twice to generate force versus time curve. The textural parameters of hardness, adhesiveness, springiness, cohesiveness, gumminess, and chewiness were determined. At least ten measurements were recorded for each type of gel. The average values of experiments were reported.

\subsection{Statistical analysis}

All historical datas were employed to linear, interactive and quadratic effects of independent experimental varibles maximum holding temperature and concentration of molasses.

The three dimensional surface presentations of each response were graphed and analysed using Design Expert (Software Version 10, Stat-Ease, Inc., Minneapolis, MN, USA). Analysis of variance (ANOVA) was performed. The $\mathrm{p}$ value less than 0.05 were considered as statistically significant.

\section{Results and discussion}

The following values were obtained for molasses of grape and carob cultivars, respectively: glucose 30.9 and $13.6 \mathrm{~g} / \mathrm{L}$, fructose 29 and $10.6 \mathrm{~g} / \mathrm{L}$, sucrose non defined and $32.4 \mathrm{~g} / \mathrm{L}$, soluble brix $72.3^{\circ}$ and $72.5^{\circ}$ Brix (Table 2). 
Table 2. The sugar contents of grape and carob molasses.

\begin{tabular}{lcccc}
\hline & $\begin{array}{c}\text { Glucose } \\
(\mathrm{g} / \mathrm{L})\end{array}$ & $\begin{array}{c}\text { Fructose } \\
(\mathrm{g} / \mathrm{L})\end{array}$ & $\begin{array}{c}\text { Sucrose } \\
(\mathrm{g} / \mathrm{L})\end{array}$ & $\begin{array}{c}\text { Soluble solids } \\
\left({ }^{\circ} \mathrm{Brix}\right)\end{array}$ \\
\hline Grape molasses & 30.9 & 29 & $\mathrm{nd}$ & 72.30 \\
Carob molasses & 13.6 & 10.6 & 32.4 & 72.50 \\
\hline
\end{tabular}

nd $=$ non defined.
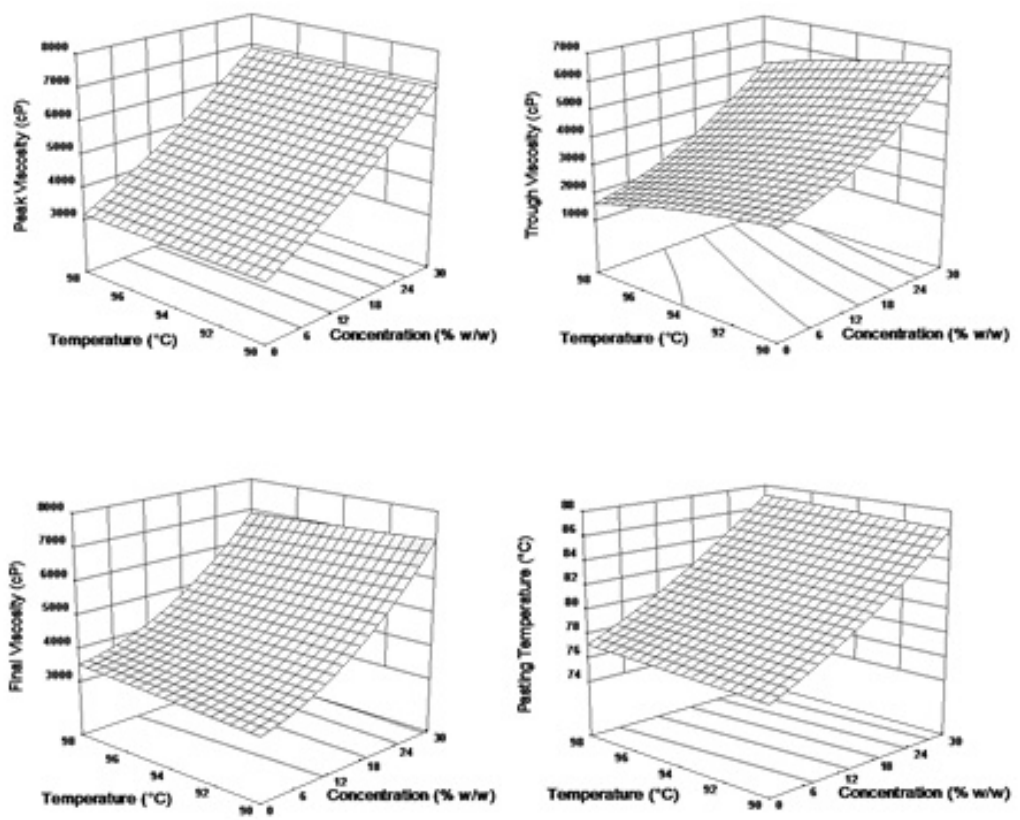

Figure 1. Effect of concentration of grape molasses and holding temperature on pasting properties of corn starch gels.
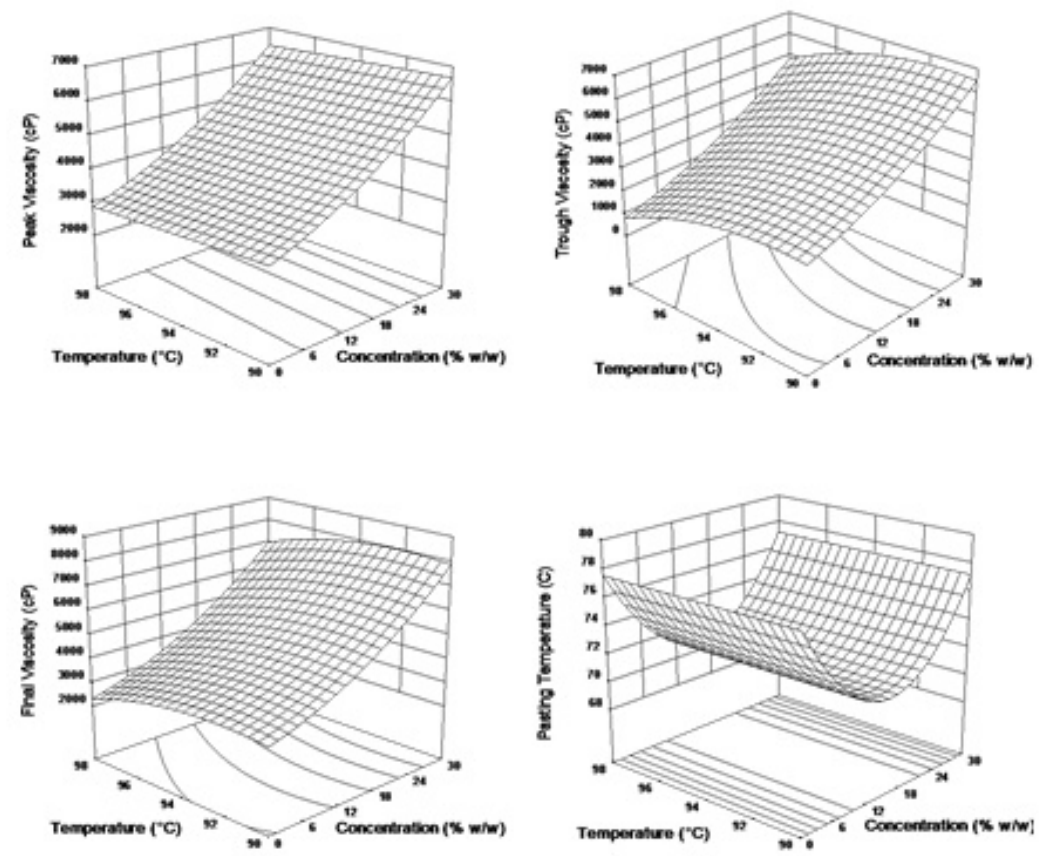

Figure 2. Effect of concentration of grape molasses and holding temperature on pasting properties of wheat starch gels. 

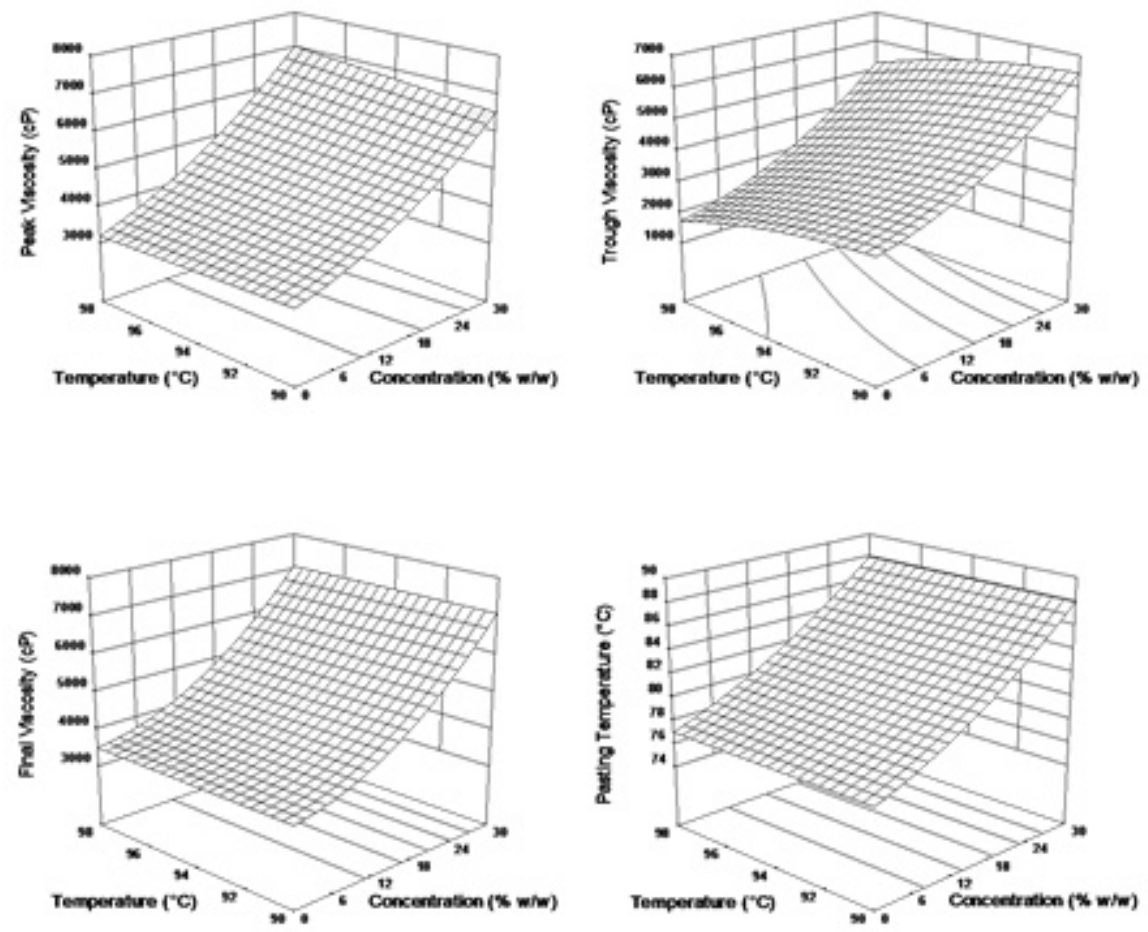

Figure 3. Effect of concentration of carob molasses and holding temperature on pasting properties of corn starch gels.
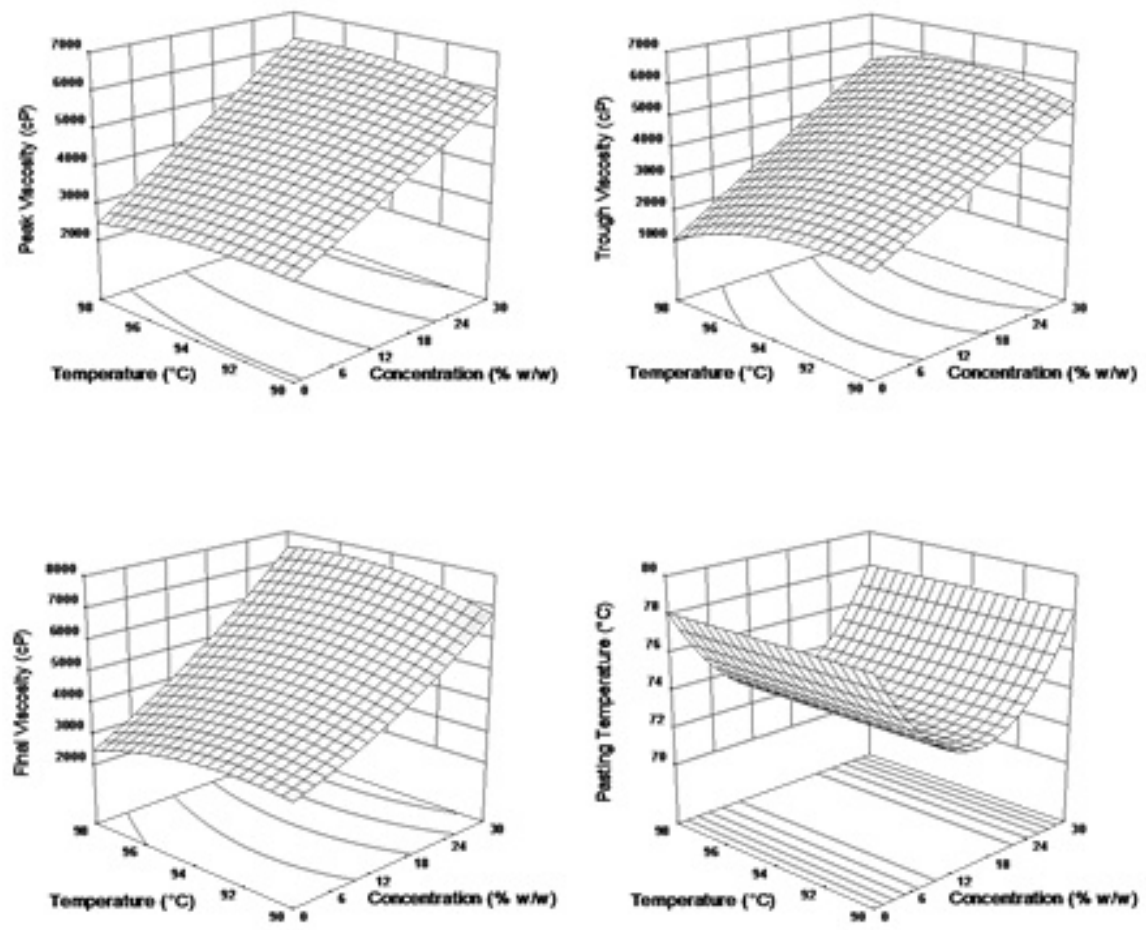

Figure 4. Effect of concentration of carob molasses and holding temperature on pasting properties of wheat starch gels. 
Effect of concentration of grape molasses and holding temperature on pasting properties of corn/wheat starch gels

PV value of CG gels were in the range of 3106 to $7078 \mathrm{cP}$ while that of WG gels changed between 2550 and $6650 \mathrm{cP}$ (Figure 1). The PV of CG gels increased as the concentration of grape molasses increased but remained constant as the holding temperature increased. The positive effects of concentration of grape molasses on increasing PV of WG gels declined sightly at the higher holding temperature. Both CG and WG gels that increase in PV with increasing grape molasses concentrations (from 0 to $30 \%$ ) might interpreted as increasing the swelling power of the starch and rupture of starch granules in the presence of sugar. PV of the different starches increase with addition of glucose and sucrose which was reported by Gunaratne et al. (2007) All the CG gels had a substantial, higher PV than all WG gels. The PV are in accordance with Li et al. (2014) who demonstrated the higher value of PV for corn starch. Bonding forces of starch varieties within the granules could also influence their swelling behavior (Pongsawatmanit et al., 2002). The strong bonding force in wheat starch resulted in slower swelling than the weaker bonding forces in corn.

TV, known as hot paste viscosity, which is the viscosity at the end of holding time at $95^{\circ} \mathrm{C}$ (Iwe \& Agiriga, 2014), CG gels varied between $1673 \mathrm{cP}$ for $\left(0 \%\right.$ and $\left.98^{\circ} \mathrm{C}\right)$ and $6467 \mathrm{cP}$ for $\left(30 \%\right.$ and $\left.92^{\circ} \mathrm{C}\right)$. The PV of WG gels increased with an increase in concentration of grape molasses and decreasing in holding temperature and were in the range $1091-6372 \mathrm{cP}$. Starches whose amylose portion leaches out into the aqueous phase more quickly have been shown to readily undergo reassociation, leading to higher hot paste viscosities (Iwe \& Agiriga, 2014).

FV can be indicated as influencing the texture and stability of the starch food products (Pongsawatmanit et al., 2002). FV values of CG and WG gels changed from 3124 to 7263 and 2460 to 7775 , respectively. With the increase in carob molasses contents from 0 to $30 \%$, the FV of CG gels increased however the FV of CG gels changed slightly as the holding temperature increased. The plot of FV at CG and WG gels showed similar trend. The high FV exhibited by gels from $20 \%$ and $95^{\circ} \mathrm{C}$ makes them more suitable for final product. Process parameters such as temperature and concentration result in changes in viscosities of gel products (Iwe \& Agiriga, 2014). During the holding temperature, the fragile swollen granules disintegrate under the shear conditions of the instrument, and the viscosity decreases to a trough viscosity. The degree of fragmentation depends on the shear rate, shear time, and nature of the starch granules (BeMiller, 2011). The higher final viscosity with less shear thinning that occurs at higher sugar concentrations does not necessarily mean that the cooled gel would have a rigid form. The effect of increases in sucrose concentration is influenced by the increase in viscosity at the pasting temperature (Kim \& Walker, 1992).

Pasting temperature is another parameter, which is a measure of minimum temperature required to cook a given foodstuff (Iwe \& Agiriga, 2014). Increased grape molasses concentration significantly altered the pasting temperature of the corn starch which ranged between 75.9 and $86.6^{\circ} \mathrm{C}$. However, with increased grape molasses concentration, pasting temperature of wheat starch gels decreased initially and increased. The relation between pasting temperature and sugar concentration significantly depends on sugar and starch types. Similar results were also reported by Sun et al. (2014) and Yildiz et al. (2015).

The viscoelastic properties of different origin starches was determined that potato, cassava and mung bean starches were higher than corn and wheat starches. By determining the rheological properties of gels investigate the relationships between pasting properties of various starches and rheological properties of their respective gels. The application holding temperatures provide differences in the bonding forces between the double helices forming the amylopectin crystallites that change the ordering of hydrogen bonds within the starch molecules (Li et al., 2014).

\section{Effect of corn/wheat starch, concentration of carob molasses and holding temperature on pasting properties of gels}

Viscosity profiles of CC (Figure 3) showed the same trend as WC gels for peak, trough and final viscosities. However, pasting temperature of gels are different from each other. $\mathrm{PV}$ value of CC gels were in the range of 3106 to $7033 \mathrm{cP}$ while that of WC gels changed between 2522 and $6537 \mathrm{cP}$. TV values of CC and WC gels changed from 1673 to 6391 and 1091 to $6130 \mathrm{cP}$, respectively. FV of CC and WC gels varied from 3156 to 7192 and 2640 to $7936 \mathrm{cP}$. With the increase in higher carob molasses concentrations, the pasting values increased, other tan the pasting temperature of both gels (CC and WC), however these gels changed slightly as the holding temperature increased. Pasting temperature plots of CC and WC look similar to CG and WG. In general, the gelatinization temperature of starch increases only with increasing sugar and starch concentration and the retrogradation is much enhanced (Pongsawatmanit et al., 2002; Sun et al., 2014). It seems that despite having different sugars, the molasses provided the liquid phase, and the hydroxyl groups in its components would have bonded with the hydrogen bonds in the starch. This resulted in providing characteristic of gel in the starch-water-sugar systems.

\subsection{TPA results}

The textural properties of starch-molasses gels prepared were deteremined using texture profile analysis curves and were noticeably affected by both concentration and temperature. It can be observed (Figures 5-8) that, the response surfaces for textural variables (hardness, cohesiveness, adhesiveness, springness) of the starch-molasses gels depended on the amount of the molasses and different holding temperatures.

Effect of varieties of starch, concentration of grape molasses and holding temperature on textural properties of gels

The interaction between grape molasses concentrations and holding temperatures for the textural values of corn and wheat starch gels are shown in Figure 1 and 2, respectively.

The hardness values of CG and WG gels ranged from 9.22 to 21.84 and 7.24 to $18.59 \mathrm{~N}$, respectively. With the increase in grape molasses contents from 0 to $30 \%$, the hardness values of CG and WG gels increased. However, by increasing the holding temperature from 90 to $98^{\circ} \mathrm{C}$, the hardness values of CG and WG gels increased initially and then decreased, with 

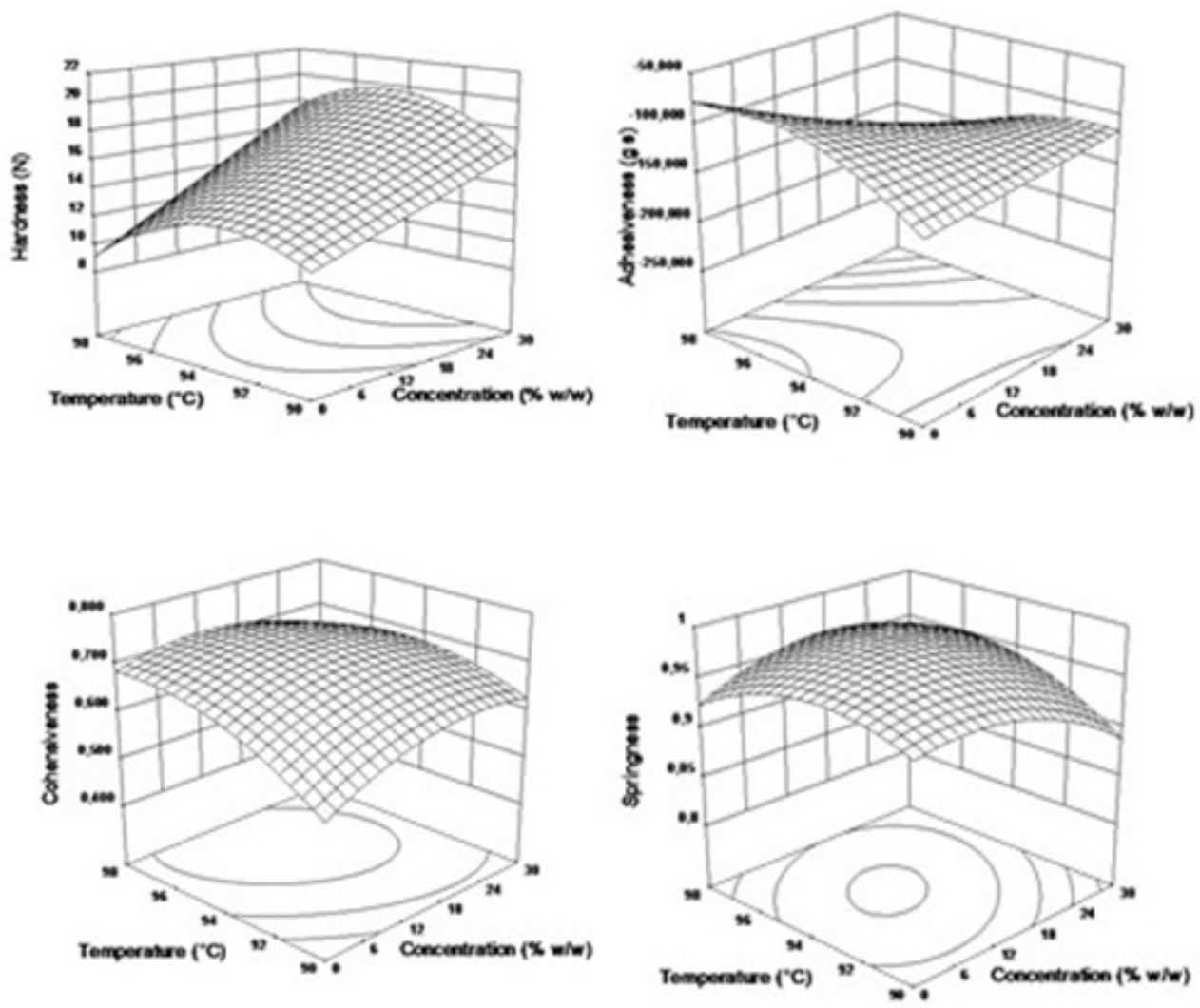

Figure 5. Effect of concentration of grape molasses and holding temperature on textural properties of corn starch gels.
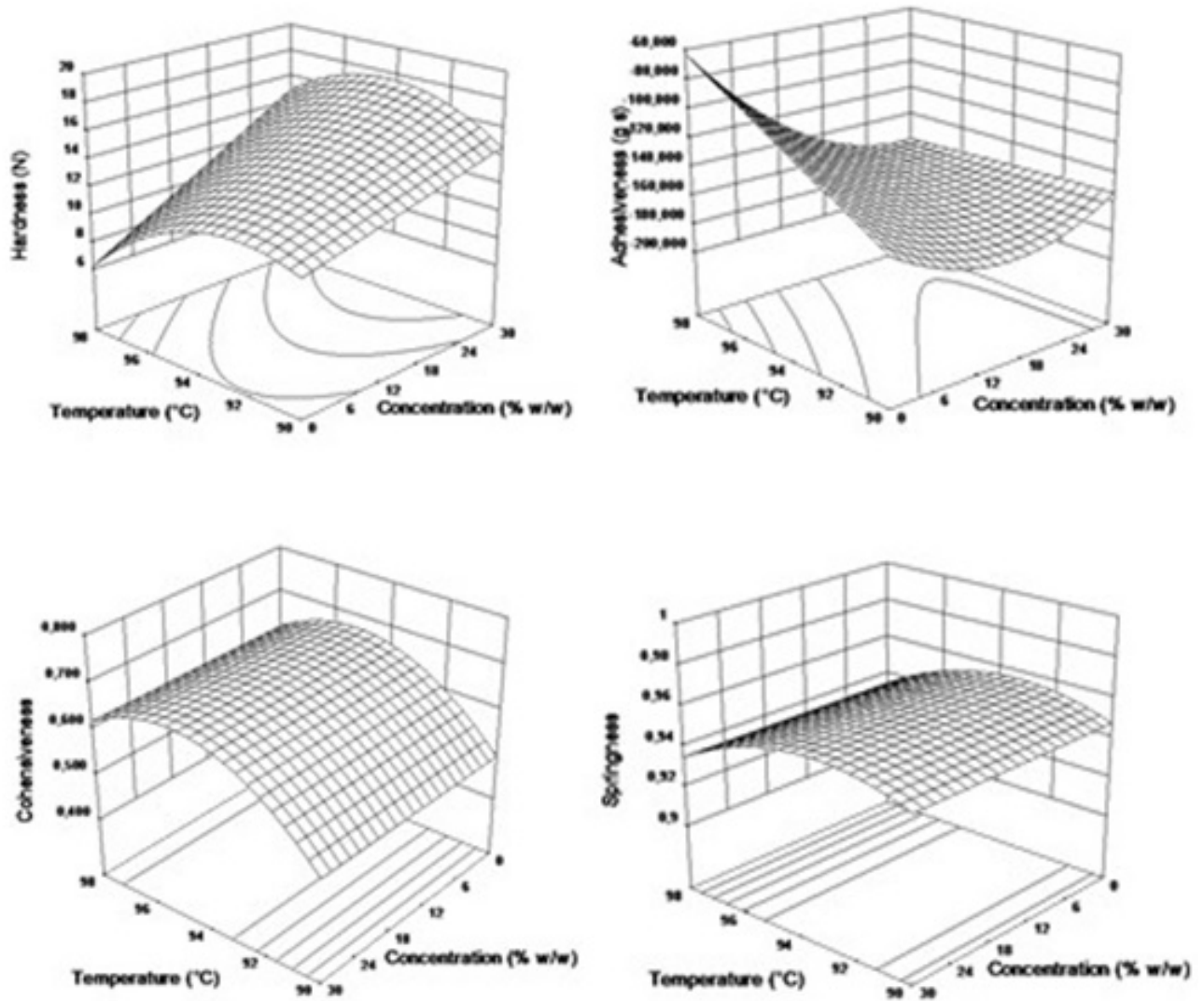

Figure 6. Effect of concentration of grape molasses and holding temperature on textural properties of wheat starch gels. 

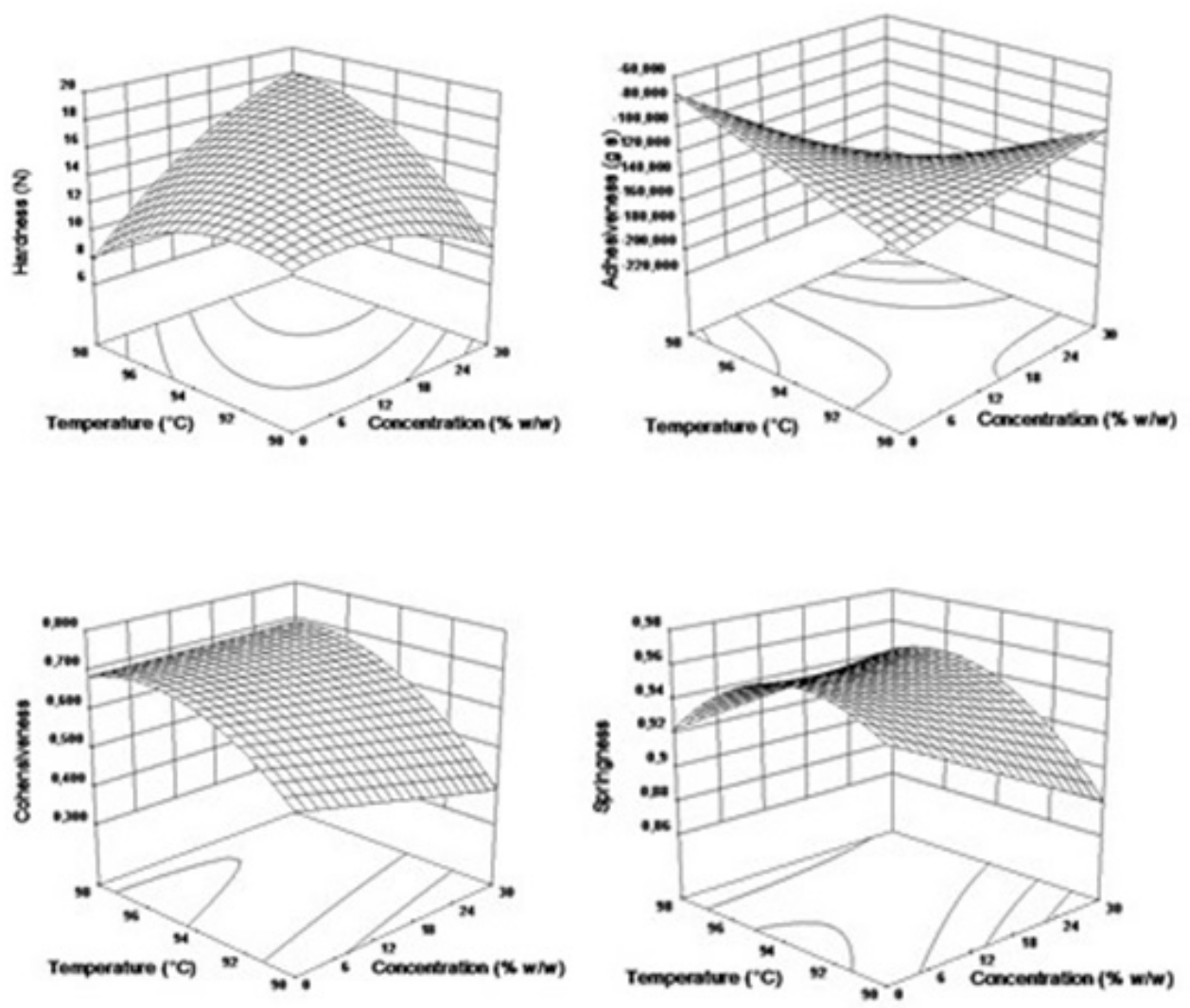

Figure 7. Effect of concentration of carob molasses and holding temperature on textural properties of corn starch gels.
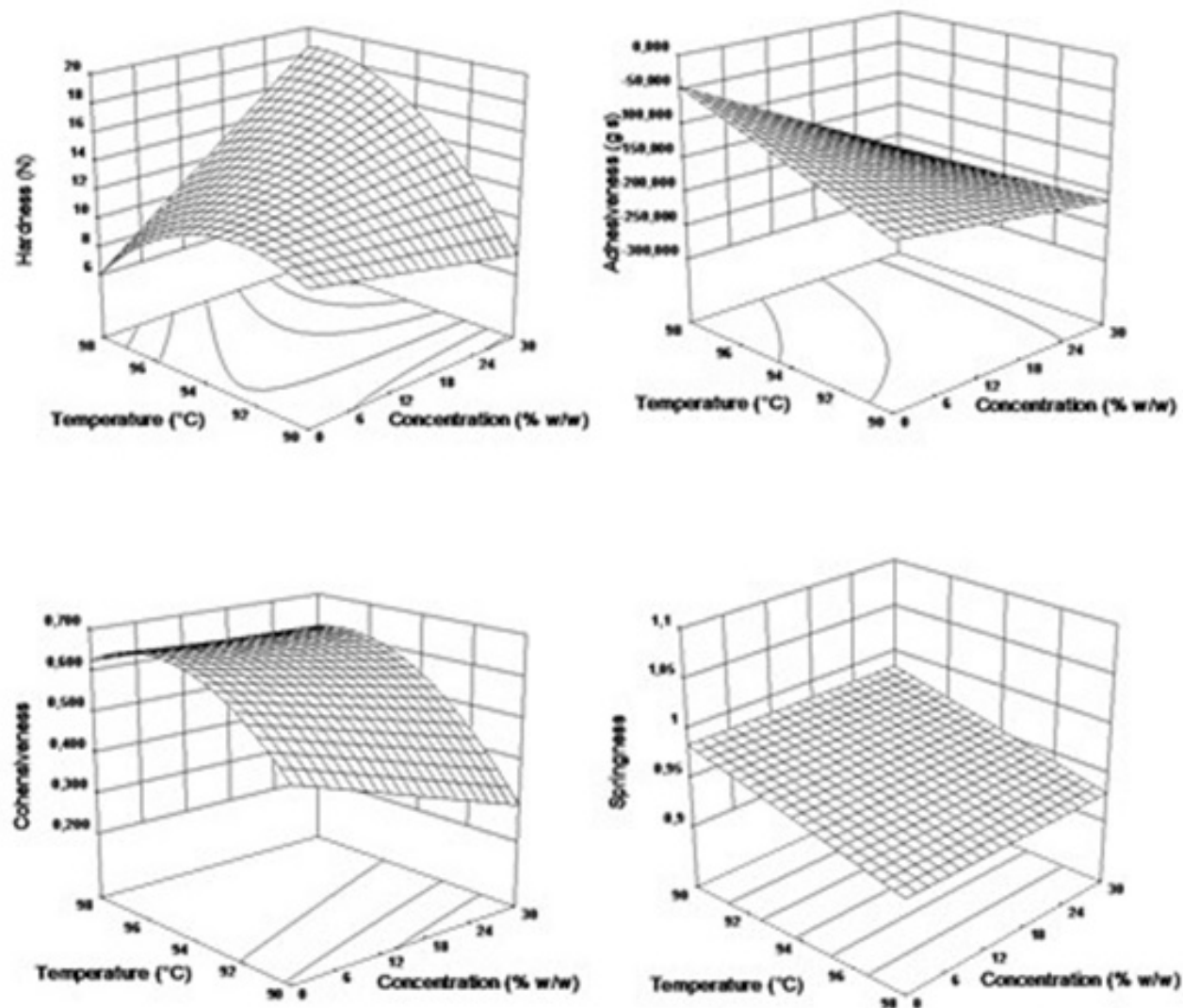

Figure 8. Effect of concentration of carob molasses and holding temperature on textural properties of wheat starch gels. 
the maximum hardness values obtained at approximately $95^{\circ} \mathrm{C}$. The gel obtained from the corn starch, at $30 \%$ concentration and $95^{\circ} \mathrm{C}$ showed the highest hardness $(21.85 \mathrm{~N})$, whereas the gel from the wheat starch with $0 \%$ concentration and $98{ }^{\circ} \mathrm{C}$, showed the lowest hardness $(7.24 \mathrm{~N})$. This is in agreement with the fact that an increase in sugar concentration resulted in a harder gel, due to the effect of sugar concentration interacting with corn starch chains in the amorphos regions of starch granules to stabilize the gels (Sun et al., 2014). These results are in accordance with (Li et al., 2014; Wang et al., 2016) which showed that all corn starch gels have a higher hardness than all wheat starch gel, because the increased swelling power of the corn starch granules give a more concentrated solution of amylose in the continuous phase of corn, as opposed to wheat starch.

Adhesiveness is defined as the negative force area for under the curve obtained between cycles. The adhesiveness values of CG gels varied between 69,14 and $228,06 \mathrm{~N} \mathrm{~s}$. As the holding temperature increased from 90 to $98{ }^{\circ} \mathrm{C}$, the adhesiveness of CG gels prepared with 1 and 5\% grape molasses, increased. However, no clear trend was observed in the CG gels prepared with an increase in the concentrations of grape molasses. Adhesiveness values tend to decrease with an increase concentration of grape molasses and an increase of holding temperature. The adhesiveness values of WG gels ranged from 64.56 to $198.53 \mathrm{~N} \mathrm{~s}$. With increasing holding temperature from 90 to $98^{\circ} \mathrm{C}$, adhesiveness values of WG gels increased. However, with the increase in grape molasses contents from 0 to $30 \%$, adhesiveness values of WG gels decreased initially, then decreased and finally increased. The results of CG and WG gels suggest that minimum adhesiveness would be and, obtained at grape molasses content 1 and $0 \%$ and holding temperature both of them $95^{\circ} \mathrm{C}$, respectively. Maximum adhesiveness of CG and WG gels, on the other hand, would be obtained at grape molasses content 30 and $20 \%$ and holding temperature 98 and $90{ }^{\circ} \mathrm{C}$, respectively. Thus, sugars and other components (10 and 20\%) must maintain enough adhesiveness to cope with starch swelling during cooking (92 and $95^{\circ} \mathrm{C}$ ). Conversely, when sugar content decreased in a low gel moisture, the starch network can withstand the starch swelling, and as a consequence, the resulting CG and WG gels at $5 \%$ concentration of grape molasses and $98^{\circ} \mathrm{C}$ were stickier and more material was lost during pasting (Li et al., 2014). Teng et al. (2013) reported that the gel adhesiveness was not a function of the independent variables.

Cohesiveness is how well a sample withstands a second deformation relative to how it behaved under the first deformation. It measures how well the sample retains its structure after the first compression (Teng et al., 2013). In addition to viscosity and elasticity of the sample, it also includes both of the adhesive and cohesive forces. For grape molasses contents and holding temperatures, the effects of cohesiveness were quite different (Figures 5 and 6). Cohesiveness values of the CG gels changed between 0.44 and 0.71 . Both grape molasses content and holding temperature increased the cohesiveness of CG gels. Results of the independent factors had significant quatratic and interactive effects on cohesiveness. Yildiz et al. (2015) found similar results showing that cohesiveness value of corn stach and grape molasses gels ranged between 0.49 and 0.71 respectively, meaning that these gels had high plasticity and tendency toward severe textural damages. The relation between corn and cohesiveness value of the starch gel was reported by Teng et al. (2013). For this reason, increasing molasses concentration in molasses/water blend increased the resistance of the sample against deformation, which is very important for the quality of the product. The cohesiveness values of WG gels ranged from 0.43 to 0.67 . With increasing holding temperature from 90 to $98{ }^{\circ} \mathrm{C}$, adhesiveness values of WG gels increased on a curve. However, with the increase in grape molasses concentrations from 0 to $30 \%$, adhesiveness values of WG gels remained generally constant. The results of CG and WG gels suggest that minimum cohesiveness obtained at grape molasses content $0 \%$ and holding temperature $90^{\circ} \mathrm{C}$, respectively. Maximum cohesiveness of CG and WG gels would be obtained at grape molasses content $20 \%$ and holding temperature $98^{\circ} \mathrm{C}$, respectively. The gumminess values, they are the product of hardness and cohesiveness values of the gels, and are characteristic of gelled foods which have a low degree of hardness and a high degree of cohesiveness (Alishahi et al., 2015).

Springiness, also known as elasticity, refers to how well the gel physically springs back after it has been deformed during the first compression. A decrease in the springiness value, therefore, indicates that the gel elasticity is lost (Teng et al., 2013). With the increase in grape molasses contents from 0 to $30 \%$, the springiness of CG gels increased intially and then decreased. In addition, with increasing holding temperature from 90 to $98^{\circ} \mathrm{C}$, the springiness of CG gels increased initially, followed by a subsequent decrease with the maximum springiness values obtained at approximately $95^{\circ} \mathrm{C}$. The results of CG gels showed that minimum springiness (0.82) would occur at $30 \%$ grape molasses, with holding temperature of $90{ }^{\circ} \mathrm{C}$ and maximum springiness $(0.98)$ could be obtained at $20 \%$ grape molasses and holding temperature of $92{ }^{\circ} \mathrm{C}$. The linear and quadratic effects of the components included in the model as well as the effects of interactions between the components on springiness value were statistically significant $(P \leq 0.05)$. These results confirmed data reported by Sun et al. (Sun et al., 2014) for corn starch with increasing glucose, fructose and maltose syrup no linear increasing or decreasing. The springiness of WG gels ranged from 0.91 to 0.98 . With increasing holding temperature from 90 to $98^{\circ} \mathrm{C}$, At first springiness of WG gels increased slightly then decreased slightly. However, with the increase in grape molasses concentrations from 0 to $30 \%$, springiness of WG gels remained stationary. The springiness plots of CG and WG were different from each other. Similar results of CG gels also were found by Alishahi et al. (2015), who reported that springiness values of all gels were in the range of 0.953-0.992 which indicates that the starch gels produced are more elastic than viscous. Springiness values of CG decreased with increase holding temperature ranging from 95 to $98^{\circ} \mathrm{C}$ and concentrations of grape molasses ranging from 20 to 30 in the blends, showing that gel elasticity is lost according to dependent of two variables. These results are in accordance with Teng et al. (2013) who reported that springiness value of the gel increased initially with increasing sugar concentration then reduced finally. 
Effect of corn/wheat starch, concentration of carob molasses and holding temperature on textural properties of gels

The interaction between carob molasses concentrations and holding temperatures for the textural values of corn and wheat starch gels are shown in Figures 3 and 4, respectively.

The hardness values of CC and WC gels ranged from 7.28 to 19.11 and 7.72 to $19.55 \mathrm{~N}$, respectively. With the increase in carob molasses contents from 0 to $30 \%$, the hardness value of CC gels increased initially, and decreased; however, the hardness of WC gels decreased linearly, with the maximum hardness obtained at around 30\% carob molasses content for all gels. Increasing holding temperature, on the other hand, primarily increased gel hardness of CC and WC gels, then decreased so that the minimum hardness values reached approximately $98^{\circ} \mathrm{C}$. As understood from Figures 7 and 8 increasing carob molasses concentration increased hardness of all gels during $98^{\circ} \mathrm{C}$ on the staright line. The experimental results of optimum hardness of CC and WG gels (15.53 and $14.70 \mathrm{~N}$ ) would be at concentration of carob molasses $20 \%$, and holding temperature $95^{\circ} \mathrm{C}$, respectively. Decreased gel hardness at higher concentration $(20 \%)$ of carob molasses in corn starch and at lower holding temperature $\left(95^{\circ} \mathrm{C}\right)$ could be viewed to the more reduction of amylose leaching that decreases the amylose concentration in the continuous phase. However, gel hardness of corn and wheat starch was not reduced despite amylose leaching was decreased at higher concentration $(20 \%)$ and higher holding temperature $\left(95^{\circ} \mathrm{C}\right)$; this shows that formation of more network and granular rigidity/deformability of starch gels could be ineffective for reducing amylose leaching, according to results which give harder gels.

The adhesiveness values of CC gels changed between 76.61 and $205.14 \mathrm{~N} \mathrm{~s}$. As the holding temperature increased from 90 to $98^{\circ} \mathrm{C}$, the adhesiveness of CG gels are prepared with $\% 1$ and 5 carob molasses incresed. However, a declining trend was observed in the CC gels prepared with an increase in the concentrations of carob molasses. Adhesiveness values tend to reduce smoothly with an increase concentration of carob molasses with increasing holding temperature. The adhesiveness values of WC gels ranged from 64.56 to $285.18 \mathrm{~N} \mathrm{~s}$. With increasing holding temperature from 90 to $98{ }^{\circ} \mathrm{C}$, adhesiveness values of WC gels increased on straight line. Furthermore, with the increase in grape molasses contents from 0 to $30 \%$, adhesiveness values of WG gels decreased slightly. The similar results of $\mathrm{CC}$ and WC gels suggest that minimum adhesiveness would be obtained at carob molasses content 30 and $0 \%$ and holding temperature 90 and $98^{\circ} \mathrm{C}$, respectively. Maximum adhesiveness of $\mathrm{CC}$ and WC would be obtained at grape molasses content 20 and $10 \%$ and holding temperature $90^{\circ} \mathrm{C}$, respectively. These process variables indicated that the gel adhesiveness decreased at highest concentration and temperature, as it was not affected by starch varities.

Cohesiveness values of CC and WC gels ranged from 0.39 to 0.72 and 0.34 to 0.66 respectively. With increasing holding temperature from 90 to $98^{\circ} \mathrm{C}$, cohesiveness values of CC and WC gels increased. However, with the increase in carob molasses contents from 0 to $30 \%$, the cohesiveness of CC and WC gels linearly decreased which implies that less energy was required for compression.
Springiness values of all gels were in the range of 0.88-1.09 which indicates that the starch gels produced are more elastic than viscous. With the increase in grape molasses contents from 0 to $30 \%$, the springiness of CC gels linearly decreased. However, with increasing holding temperature from 90 to $98^{\circ} \mathrm{C}$, springiness of CC gels linearly decreased, with the maximum springiness values obtained at approximately $95^{\circ} \mathrm{C}$. With the increasing concentration of carob molasses, the springiness of CC gels lost the rubbery mouth feel (Figure 7). From this study, the springiness values of WC gels were different from CC gels. With decreasing holding temperature from 98 to $90^{\circ} \mathrm{C}$, at first, the springiness of WC gels straightly increased. The springiness of WC gels were similar at different concentrations. These results showed that starch varieties affected strongly the springiness of gels. WC gels lost viscous and soft sludge properties at increasing temperature.

\subsection{Comparison between carob and grape molasses on gels}

The mechanisms of starch-sugar such as sucrose, glucose and fructose have been explained separately (Teng et al., 2013).

There is no evidence that the molasses related to the pasting and textural properties of the molasses-starch blends contain different combinations of sugars. Grape molasses doesn't include sucrose like in carob molasses. Sucrose has been found to affect significantly pasting and texture of gels (Kim \& Walker, 1992). This is in agreement with observed results for both corn and wheat starches. Pasting property values for carob molasses-starch systems were higher than grape molasses-starch systems. It therefore means that disaccharides increase pasting properties more than monosaccharides. In addition sucrose has more interactions with starch chains than glucose and fructose as it contains more binding sites (Kim \& Walker, 1992; Pongsawatmanit et al., 2002) . It could be inferred that an increase in the sucrose content of the carob molasses increases pasting values.

With holding temperature of $90-98^{\circ} \mathrm{C}$, all pasting parameters were affected, not including pasting temperature. All samples which determined maximum temperature were reached, were affected all pasting parameters. Although the peak, final and also though viscosities continued to decline and the viscosity parameters, brekdown and setback reached to increase, even with increasing the holding temperatures.

\section{Conclusion}

In this work, the effects of process parameters on the quality of starch-molasses blends were investigated. The increase of molasses proportion generally caused an increase in textural parameters. Textural properties of carob molasses-wheat starch interactions are affected more highly than grape molasses-wheat starch interactions. The carob molasses had a positive effect on increasing peak viscosity, trough viscosity and final viscosity. The carob molasses had plasticizing effect due to containing sucrose. Sucrose might have increased the water availability of starch for conversion to gel form. All corn starch gels have a higher hardness than all wheat starch gels. With changing holding temperature of $90-98^{\circ} \mathrm{C}$, all pasting parameters for all samples were affected, not including pasting temperature. 
The processing conditions for an optimum parameter of gel were found at wheat starch, carob molasses $20 \%$, and holding temperature of $92{ }^{\circ} \mathrm{C}$. The WC gel has suitability for use in the food industry production. It could be used especially for children, sportsmen, elderly and in situations demanding immediate energy to produce due to its remarkable nutritional, health and economic value.

\section{References}

Akkaya, Z., Schröder, J., Tavman, S., Kumcuoglu, S., Schuchmann, H. P., \& Gaukel, V. (2012). Effects of spray drying on physical properties, total phenolic content and antioxidant activity of carob molasses. International Journal of Food Engineering, 8(4), 1-13. http://dx.doi. org/10.1515/1556-3758.2593.

Alasalvar, C., Al-Farsi, M., \& Shahidi, F. (2005). Compositional characteristics and antioxidant components of cherry laurel varieties and pekmez. Journal of Food Science, 70(1), 47-52. http://dx.doi. org/10.1111/j.1365-2621.2005.tb09064.x.

Alishahi, A., Farahnaky, A., Majzoobi, M., \& Blanchard, C. L. (2015). Physicochemical and textural properties of corn starch gels: effect of mixing speed and time. Food Hydrocolloids, 45, 55-62. http:// dx.doi.org/10.1016/j.foodhyd.2014.11.005.

Baek, M. H., Yoo, B., \& Lim, S. T. (2004). Effects of sugars and sugar alcohols on thermal transition and cold stability of corn starch gel. Food Hydrocolloids, 18(1), 133-142. http://dx.doi.org/10.1016/ S0268-005X(03)00058-4.

BeMiller, J. N. (2011). Pasting, paste, and gel properties of starchhydrocolloid combinations. Carbohydrate Polymers, 86(2), 386-423. http://dx.doi.org/10.1016/j.carbpol.2011.05.064.

Chang, Y., Lim, S. T., \& Yoo, B. (2004). Dynamic rheology of corn starchesugar composites. Journal of Food Engineering, 64(4), 521527. http://dx.doi.org/10.1016/j.jfoodeng.2003.08.017.

Cho, S.-A., \& Yoo, B. (2010). Comparison of the effect of sugars on the viscoelastic properties of sweet potato starch pastes. International Journal of Food Science \& Technology, 45(2), 410-414. http://dx.doi. org/10.1111/j.1365-2621.2009.02146.x.

Gunaratne, A., Ranaweera, S., \& Corke, H. (2007). Thermal, pasting, and gelling properties of wheat and potato starches in the presence of sucrose, glucose, glycerol, and hydroxypropyl $\beta$-cyclodextrin. Carbohydrate Polymers, 70(1), 112-122. http://dx.doi.org/10.1016/j. carbpol.2007.03.011.

Iwe, M. O., \& Agiriga, A. N. (2014). Pasting properties of ighu prepared from steamed varieties of cassava tubers. Journal of Food Processing and Preservation, 38(6), 2209-2222. http://dx.doi.org/10.1111/ jfpp.12201.

Kim, C. S., \& Walker, C. E. (1992). Changes in starch pasting properties due to sugars and emulsifiers as determined by viscosity measurement. Journal of Food Science, 57(4), 1009-1013. http:// dx.doi.org/10.1111/j.1365-2621.1992.tb14344.x.

Li, S., Zhang, Y., Wei, Y., Zhang, W., \& Zhang, B. (2014). Thermal, pasting and gel textural properties of commercial starches from different botanical sources. Journal of Bioprocessing \& Biotechniques, 4, 161.

Ozcan, M. M., Arslan, D., \& Gökçalik, H. (2007). Some compositional properties and mineral contents of carob (Ceratonia siliqua) fruit, flour and syrup. International Journal of Food Sciences and Nutrition, 58(8), 652-658. http://dx.doi.org/10.1080/09637480701395549. PMid:17852490.

Pongsawatmanit, R., Thanasukarn, P., \& Ikeda, S. (2002). Effect of sucrose on RVA viscosity parameters, water activity and freezable water fraction of cassava starch suspensions. Science Asia, 28(2), 129134. http://dx.doi.org/10.2306/scienceasia1513-1874.2002.28.129.

Sengül, M., Fatih Ertugay, M., Sengül, M., \& Yüksel, Y. (2007). Rheological characteristics of carob pekmez. International Journal of Food Properties, 10(1), 39-46. http://dx.doi.org/10.1080/10942910600627996.

Sert, D., Yilmaz, M. T., Karakaya, M., \& Bayrak, E. (2009). Pekmezdairy desserts fortified with spray-dried dairy powders: effects of the interaction between skim milk powder, yoghurt powder and buttermilk powder by a mixture design approach. Journal of Texture Studies, 40(5), 606-622. http://dx.doi.org/10.1111/j.17454603.2009.00200.x.

Sun, Q., Xing, Y., Qiu, C., \& Xiong, L. (2014). The pasting and gel textural properties of corn starch in glucose, fructose and maltose syrup. PLoS One, 9(4), e95862. http://dx.doi.org/10.1371/journal. pone.0095862. PMid:24755772.

Teng, L. Y., Chin, N. L., \& Yusof, Y. A. (2013). Rheological and textural studies of fresh and freeze-thawed native sago starch-sugar gels. II. Comparisons with other starch sources and reheating effects. Food Hydrocolloids, 31(2), 156-165. http://dx.doi.org/10.1016/j. foodhyd.2012.11.002.

Wang, L., Xu, J., Fan, X., Wang, Q., Wang, P., Zhang, Y., Cui, L., Yuan, J., \& Yu, Y. (2016). Effect of disaccharides of different composition and linkage on corn and waxy corn starch retrogradation. Food Hydrocolloids, 61, 531-536. http://dx.doi.org/10.1016/j.foodhyd.2016.06.010.

Yildiz, O., Yurt, B., Toker, O. S., Ceylan, M. M., Yilmaz, M. T., \& Bastürk, A. (2015). Pasting, textural and sensory characteristics of the kofter, a fruit-based dessert: effect of molasses and water concentration. International Journal of Food Engineering, 11(3), 349-358. 